\title{
PERANCANGAN PROTOTYPE APLIKASI KNOWLEDGE MANAGEMENT PADA DIVISI MANAGEMENT AUTOMATION INFORMATION UNTUK MENDUKUNG ORACLE FINANCIAL PADA ORANG TUA GROUP
}

\author{
Gema; Celline Liawan; Gerardus Polla \\ Jurusan Matematika Statistik, Fakultas Sains dan Teknologi, Bina Nusantara University \\ Jln. KH Syahdan No 9, Kemanggisan, Palmerah, Jakarta Barat 11480 \\ GerardP@binus.edu
}

\begin{abstract}
The purpose of this project is to design a knowledge management application as a media to document knowledge and facility that supported a knowledge sharing culture in Oracle Financial subdivision in Orang Tua Group. The researcher uses 7 first steps method which defined by Tiwana in doing knowledge management application prototype. The knowledge management prototype application modules consist of Wiki page, document library, discussion board, blog, picture library, knowledge base, help desk, frequently asked questions, and surveys. In using knowledge in knowledge base, user will get knowledge through business process, how to use the application, or how to finish some cases. Knowledge management prototype application design as a whole could fulfill user's needs in sharing knowledge, but still needs continuous improvement for maximal usage.
\end{abstract}

Keywords: prototype design, knowledge management application, knowledge

\begin{abstract}
ABSTRAK
Tujuan dari proyek ini adalah untuk merancang suatu aplikasi knowledge management sebagai media untuk pendokumentasian knowledge dan sarana yang dapat mendukung suatu budaya knowledge sharing pada subdivisi Oracle Financial di Orang Tua Group. Peneliti menggunakan metode 7 langkah pertama yang diuraikan oleh Tiwana dalam melakukan perancangan prototype aplikasi knowledge management. Adapun rancangan modul-modul prototype aplikasi knowledge management meliputi Wiki page, document library, discussion board, blog, picture library, knowledge base, help desk, frequently asked questions, dan surveys. Dengan menggunakan knowledge yang disimpan pada knowledge base, user diharapkan dapat memperoleh pengetahuan mengenai proses bisnis, cara penggunaan aplikasi, ataupun cara-cara untuk menyelesaikan kasus. Perancangan prototype aplikasi knowlegde management ini secara keseluruhan sudah dapat memenuhi kebutuhan user dalam berbagi knowledge, namun pengembangan berkelanjutan masih diperlukan agar aplikasi dapat digunakan secara maksimal.
\end{abstract}

Kata kunci: perancangan prototipe, aplikasi knowledge management, knowledge

\section{PENDAHULUAN}

Perkembangan bisnis dan teknologi bergerak sangat cepat, knowledge menjadi salah satu kebutuhan primer bagi suatu perusahaan untuk meningkatkan efektivitas proses bisnisnya. Namun perlu disadari, bahwa implementasi dan sosialisasi pentingnya berbagi knowledge ini bukanlah suatu proses yang mudah. Kebanyakan karyawan di perusahaan sibuk dengan pekerjaannya masing-masing dan menjadi tidak terlalu peduli untuk mendokumentasikan ataupun berbagi knowledge yang mereka dapatkan pada saat menjalankan tanggung jawabnya, sehingga jika suatu saat karyawan menghadapi kasus serupa, ia tidak mempunyai referensi mengenai solusi apa yang ia pernah terapkan dulu dan akibatnya harus melakukan analisis dari awal kembali. Di sinilah fungsinya suatu Knowledge Management (KM) untuk menjaga agar knowledge yang berharga dari suatu organisasi dapat digunakan kembali ataupun tidak hilang dikarenakan beberapa hal seperti pergantian karyawan.

Orang Tua (OT) Group merupakan perusahaan produsen consumer goods yang tengah berkembang saat ini. Untuk mendukung proses bisnisnya, pada tahun 2000 dibangun divisi IT dengan nama Management Automation Information (MAI). Pada divisi MAI di OT saat ini belum ada suatu aplikasi KM yang dapat digunakan sebagai media dokumentasi user manual, report, ataupun kasus-kasus yang pernah terjadi, yang nantinya dapat menunjang proses berbagi pengetahuan. Khususnya pada subdivisi Oracle Financial (Orafin) yang modul-modulnya meliputi Account Payable $(A P)$, Account Receivable (AR), General Ledger (GL), Fixed Asset (FA), dan Cash Management (CM), setiap bulannya pada saat penutupan periode pembukuan sering terjadi kasus seperti selisih antar modul, selisih karena ada kesalahan input sehingga data tidak muncul di report tertentu, ataupun error dari sistem, karena itu peneliti ingin memfokuskan proyek ini pada perancangan prototype aplikasi KM sebagai knowledge base untuk menyimpan solusi dari kasus-kasus yang terjadi, dokumentasi user manual sebagai sarana online training, serta dokumentasi dari laporan-laporan Orafin, sehingga knowledge yang tersimpan dapat digunakan kembali untuk menyelesaikan kasus, serta dapat diakses dengan mudah dan cepat.

Tujuan yang ingin dicapai pada proyek perancangan prototype aplikasi KM ini adalah: (1) menyediakan media dokumentasi user manual dan kasus-kasus yang pernah 
terjadi yang lebih terstruktur dan mudah untuk diakses; (2) menyediakan fitur helpdesk yang dapat menangani masalah dengan lebih baik dan mudah di-monitoring; (3) menyimpan knowledge dan pengalaman yang dimiliki karyawan di dalam aplikasi KM, agar pengetahuan karyawan tersebut tidak hilang ketika ia keluar dari perusahaan; (4) mendukung suatu budaya knowledge sharing untuk saling berbagi pengetahuan dengan adanya KM.

Sedangkan manfaat yang diharapkan dari proyek ini adalah: (1) dengan aplikasi KM sebagai pendukung knowledge sharing, ketika diimplementasikan user diharapkan dapat memperoleh pengalaman dan pengetahuan dalam menangani kasus; (2) mengurangi waktu yang dibutuhkan oleh staff Orafin dalam menyelesaikan kasus dengan menggunakan solusi yang sebelumnya sudah pernah ditemukan; (3) meminimalkan waktu dari staff Orafin untuk training user baru dengan memberikan akses user manual yang ada pada aplikasi; (4) hasil dari perancangan prototype aplikasi KM ini dapat digunakan oleh divisi MAI sebagai acuan untuk mengembangan sistem KM pada organisasi OT Group.

Pada proyek ini, peneliti membatasi ruang lingkupnya hanya pada subdivisi Oracle Financial. Adapun pembahasan yang akan dilakukan yaitu pembahasan konsep dan dasar teori $\mathrm{KM}$, menyusun langkah-langkah untuk merancang prototype aplikasi KM pada subdivisi Orafin di OT Group, membuat aplikasi prototype KM, merancang workflow dari penggunaan aplikasi KM, evaluasi untuk mengukur keberhasilan proyek ini.

\section{Rumusan Permasalahan}

Masalah-masalah yang ada pada divisi MAI, khususnya Orafin dapat dirumuskan dengan (1) bagaimanakah caranya agar user manual, dokumen-dokumen lainnya, serta solusi dari kasus-kasus yang pernah terjadi dapat didokumentasikan dan didistribusikan kepada semua user; (2) bagaimana caranya agar setiap masalah yang terjadi, dapat lebih mudah di-monitoring dan di-manage; (3) bagaimanakah caranya menjaga agar knowledge yang dimiliki oleh perusahaan tidak hilang karena adanya pergantian karyawan; (4) bagaimanakah caranya memotivasi karyawan baik untuk meningkatkan knowledge-nya sendiri ataupun berbagi knowledge yang dimilikinya?

\section{METODE PENELITIAN}

Untuk metodologi dalam merancang prototype aplikasi knowledge management di subdivisi Orafin, peneliti menggunakan 7 langkah pertama dari The 10 Steps Knowledge Management Road Map yang diuraikan oleh Tiwana (2002) seperti pada Gambar 1.

Fase terakhir adalah evaluasi rancangan prototype untuk mengukur keberhasilan rancangan apakah sudah sesuai dengan tujuan dan kebutuhan dari perancangan, serta agar dapat dilakukan pengembangan berkelanjutan dari hasil evaluasi.

\section{HASIL DAN PEMBAHASAN}

\section{Fase Pertama: Analisis Infrastruktur}

Pada fase pertama ini, peneliti mengidentifikasi infrastruktur dan strategi bisnis dengan observasi dan interview kepada tim MAI.

\section{Langkah Pertama: Analisis Implementasi Infrastruktur yang Berjalan}

Dalam analisis infrastruktur yang berjalan peneliti membagi pembahasan menjadi dua topik utama, yaitu mengenai analisis infrastruktur teknologi yang berjalan dan analisis infrastruktur dari knowledge culture yang berjalan.

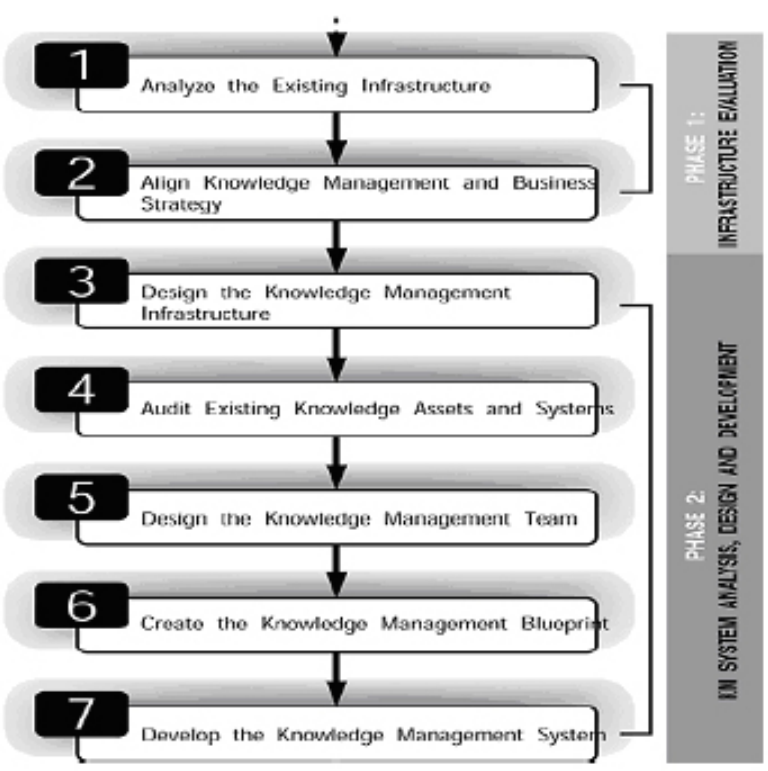

Gambar 1 Langkah-langkah Pengembangan Sistem Knowledge Management

\section{Analisis Infrastruktur Teknologi yang Berjalan}

Orang Tua Group saat ini telah menggunakan teknologi jaringan komputer untuk menghubungkan semua unit komputer, baik di antara divisi maupun kantor cabangnya. Semua komputer yang berada di kantor pusat telah terhubung langsung ke server melalui Local Area Network ( $L A N)$ dengan menggunakan switch, sedangkan untuk komputer-komputer yang berada di cabang atau pabrik terhubung ke server melalui Wide Area Network (WAN), dengan menggunakan router. Semua komputer tersebut dapat langsung mengakses aplikasi yang ada di server aplikasi. Dengan adanya teknologi jaringan komputer ini memungkinkan untuk mempermudah proses pengiriman dan pengaksesan informasi lihat Gambar 2.

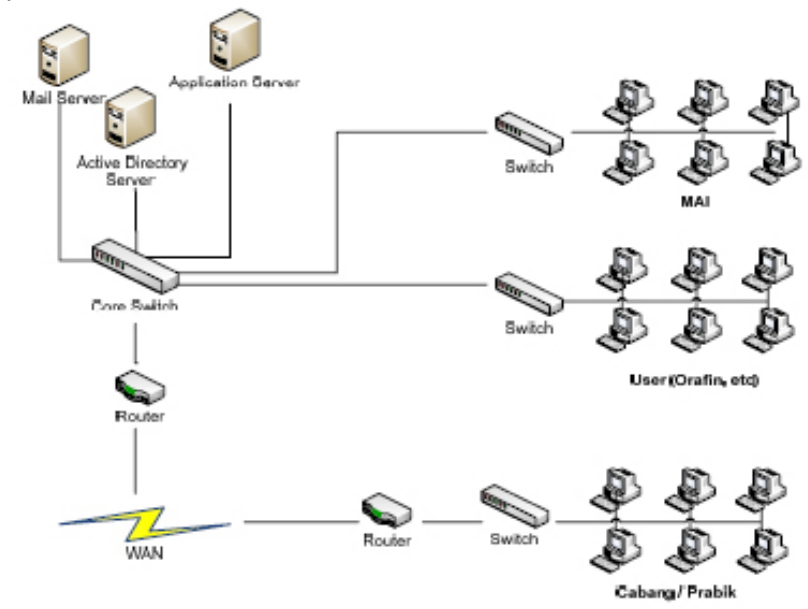

Gambar 2 Topologi Jaringan Komputer di Orang Tua Group

Teknologi yang telah dimiliki oleh OT, sebagian besar sudah dapat mendukung proses pengembangan prototype aplikasi sistem KM pada subdivisi Orafin. Jaringan komputer yang ada memungkinkan setiap user untuk dapat saling berkomunikasi, bertukar informasi, dan mengakses aplikasi 
secara remote ke kantor pusat. Server yang sudah ada juga dapat digunakan sebagai server untuk mengimplementasikan prototype aplikasi KM. Untuk media repositories, OT sudah memiliki beberapa server database, yang dapat digunakan sebagai media repositories pada prototype aplikasi KM. Hal yang diperlukan adalah menambah kapasitas media penyimpanan datanya (hard disk), supaya dapat lebih banyak menyimpan knowledge dan dokumen-dokumen perusahaan.

Berdasarkan dari hasil analisis infrastruktur yang telah dimiliki oleh OT, peneliti mencoba mendefinisikan teknologi apa saja yang diperlukan dan membuat rancangan dari arsitektur teknologi prototype aplikasi sistem KM yang akan dikembangkan.

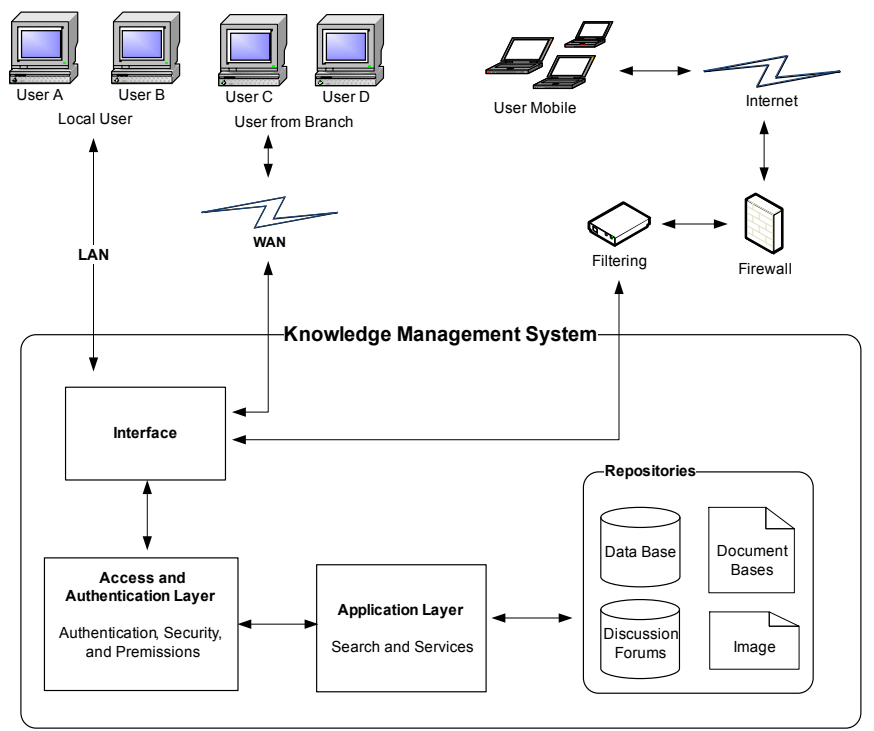

Gambar 3 Rancangan Arsitektur Teknologi Prototype Aplikasi Sistem Knowledge Management

\section{Analisis Infrastruktur Knowledge Culture yang Berjalan}

Knowledge culture yang berjalan pada subdivisi Orafin adalah umumnya terjadi pertukaran knowledge hanya pada saat training dilakukan atau ketika ada masalah yang terjadi (case based reasoning). Pada saat training, user dari divisi pembukuan dan keuangan baik yang ada di lingkup corporate ataupun yang berlokasi di masing-masing business unit diundang untuk datang ke corporate tempat training diadakan. Untuk pemecahan kasus, selama ini user lebih bergantung kepada staf Orafin sebagai knowledge source. Ketika terjadi kasus, biasanya user akan bertanya via e-mail atau telepon kepada staf Orafin untuk dicarikan solusinya. Saat ini belum ada sarana online untuk pembelajaran dari knowledge yang ada yang dapat dijadikan referensi untuk pemecahan kasus.

Dengan rancangan prototype aplikasi knowledge management pada subdivisi Orafin, diharapkan dapat mendukung proses berbagi knowledge dengan lebih efektif, di mana user dapat melakukan pembelajaran secara online di samping training face-to-face. User dapat lebih mandiri dalam menyelesaikan kasus dengan menggunakan referensi knowledge yang tersimpan pada knowledge base, serta dengan adanya forum diskusi dapat memfasilitasi user untuk berpartisipasi dalam pembahasan topik tertentu. Tentunya untuk perubahan knowledge culture ini harus didukung oleh manajeman perusahaan dalam sosialiasi budaya saling berbagi knowledge dan menjadikan implementasi prototype aplikasi knowledge management sebagai agenda perusahaan, untuk kemudian membuat kebijakan dan Standard Operating Procedure (SOP) dari penggunaan aplikasi knowledge management. Berikut usulan peneliti untuk mensosialisasikan penggunaan prototype knowledge management agar dapat membentuk knowledge culture yang lebih baik, yaitu membuat kebijakan bahwa service request kasus hanya akan dilayani jika user mengirimkannya kepada staf Orafin melalui fitur help desk, setiap kasus yang terjadi harus didokumentasikan dan di-input ke dalam knowledge base, dan memberlakukan kebijakan reward and punishment kepada user atas partisipasinya dalam pengembangan dan penggunaan prototype aplikasi knowledge management.

\section{Langkah Kedua: Menghubungkan Knowledge Management dan Strategi Organisasi}

Pada langkah kedua, peneliti mengidentifikasi tujuan dan strategi dari divisi MAI untuk menyelaraskannya dengan rancangan prototype aplikasi KM dengan tahapan yaitu (1) mengidentifikasi tujuan divisi management automation information; (2) analisis strategi pendekatan ekspansif knowledge management; (3) analisis strategic knowledge gap dengan zack framework; (4) analisis SWOT untuk prototype knowledge management. Berikut uraian dari tiap tahapan pada langkah kedua.

\section{Mengidentifikasi Tujuan Divisi Management Automation Information}

Adapun tujuan dari divisi MAI Orang Tua Group adalah sebagai berikut: (1) meningkatkan kinerja, kemudahan akses, keamanan, dan kehandalan infrastruktur dan manajemen Teknologi Informasi; (2) menyediakan layanan teknologi dan otomatisasi reporting yang efisien dan efektif; (3) menjadi penggerak proses dan teknologi inovatif untuk mentransformasi layanan MAI. Konsep KM sejalan dengan tujuan dari divisi MAI untuk meningkatkan kinerja melalui knowledge yang dimiliki oleh karyawannya, kemudahan akses, dan teknologi inovatif untuk mentransformasi layanan yang lebih baik dan cepat.

\section{Analisis Strategi Pendekatan Ekspansif Knowledge Management}

Berdasarkan hasil analisis perbandingan strategi KM personalization dan codification, maka lebih tepat jika perancangan KM pada subdivisi Orafin lebih berfokus pada pendekatan codification, yang memungkinkan penyimpanan, pemberian index, perolehan, dan penggunaan kembali knowledge, karena knowledge yang ada pada subdivisi Orafin cenderung tetap dan reusable, kecuali untuk pemecahan kasus yang mempunyai kemungkinan merupakan suatu masalah unik yang belum pernah terjadi, sehingga membutuhkan pendekatan personalization. Untuk kasus-kasus yang pernah terjadi disimpan pada knowledge base juga dapat dijadikan referensi pada pendekatan personalization untuk analisis kasus lebih lanjut. Kebutuhan akan sistem knowledge management lebih didorong karena kebutuhan untuk manajemen knowledge yang lebih baik, pendokumentasian knowledge berdasarkan kategori tertentu dan sebagai media penyimpanan knowledge, maka pengembangan knowledge berada pada kategori combination berdasarkan model SECI dari Nonaka, yaitu proses pengembangan dari eksplicit knowledge ke explicit knowledge.

\section{Analisis Strategic Knowledge Gap dengan Zack Framework}

Peneliti menggunakan Zack Framework untuk melakukan analisis mengenai strategic knowledge gap yang ada pada subdivisi Orafin, dengan menjawab empat pertanyaan 
kunci berikut: apa yang harus diketahui oleh perusahaan?; apa yang perusahaan ketahui?; apa yang harus dilakukan perusahaan?; apa yang dapat dilakukan perusahaan?; lihat Gambar 4.

\section{Analisis SWOT untuk Prototype Knowledge Management}

Menurut Thompson, Strickland, \& Gamble (2008) menilai kekuatan dan kelemahan sumber daya yang dimiliki oleh suatu perusahaan serta kesempatan dan ancaman dikenal sebagai analisis SWOT (Strength, Weakness, Opportunity, dan Threat). Untuk menghubungkan knowledge management dengan strategi perusahaan, peneliti juga melakukan analisis SWOT untuk perancangan prototype aplikasi KM yang diuraikan sebagai berikut.

Strength, poin-poin yang mendukung prototype aplikasi KM meliputi: dari segi infrastruktur divisi MAI di OT sudah mendukung untuk implementasi prototype aplikasi KM yang dirancang dan value kelima dari OT adalah innovation dan salah satu tujuan divisi MAI yaitu menjadi penggerak proses dan teknologi inovatif. Konsep dan prototype aplikasi KM sejalan dengan inovasi untuk mendukung perkembangan perusahaan ke arah yang lebih baik menjadi suatu learning organization, sehingga seharusnya penerapan KM dapat memperoleh dukungan dari manajemen.

Weakness, adapun kelemahan yang mungkin dapat

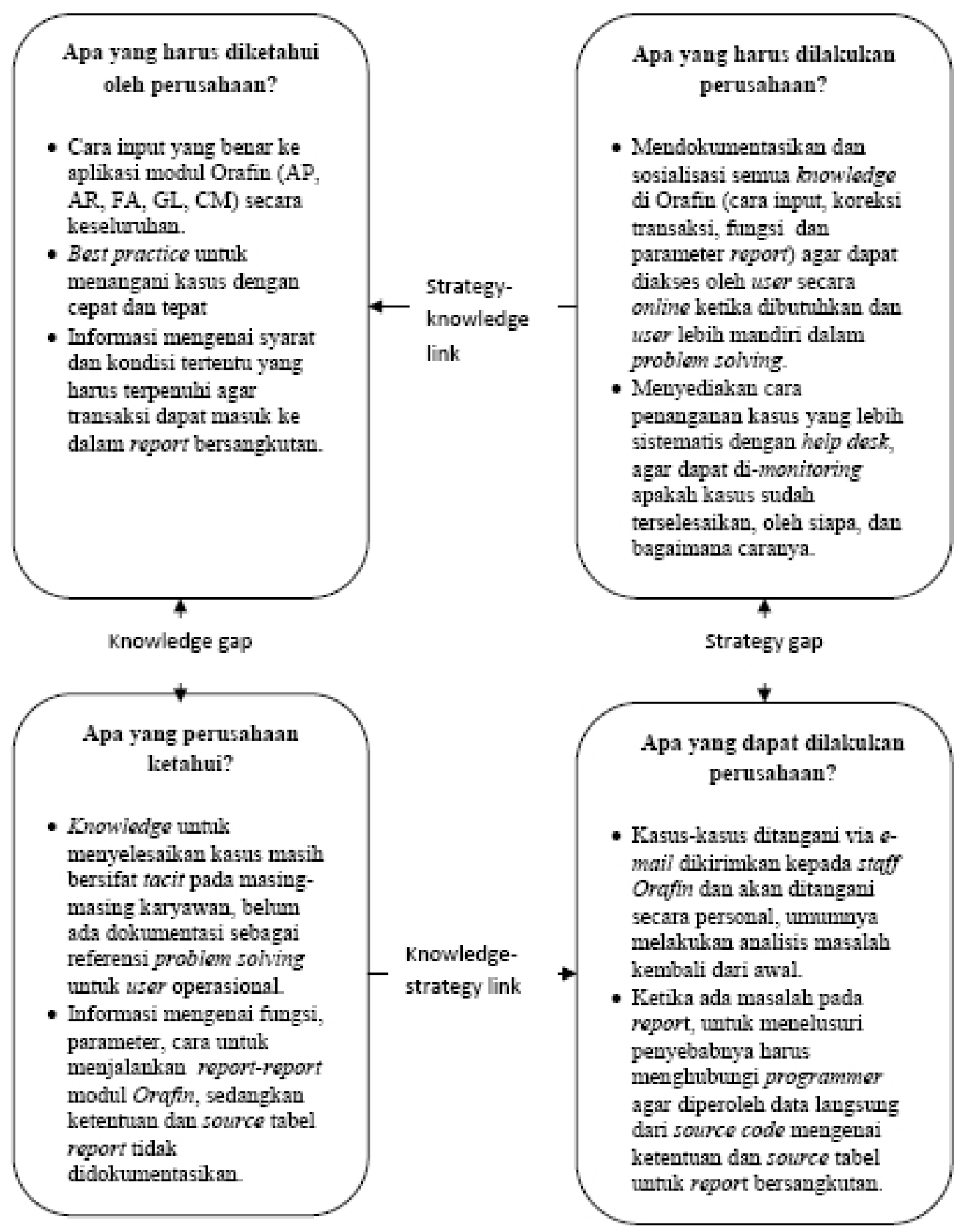

Gambar 4 Strategic knowledge gap dengan Zack Framework pada subdivisi orafin Keterangan: Isi disesuaikan berdasarkan hasil analisis pada subdivisi Orafin Orang Tua Group 
menjadi penghambat di antaranya dibutuhkan investasi tambahan, baik untuk investasi lisence software maupun tambahan waktu atau tenaga kerja untuk me-maintain aplikasi dan knowledge base agar tetap up-to-date. Opportunity, kesempatan atau peluang yang dapat diperoleh dari prototype aplikasi KM, yaitu pendokumentasikan knowledge menjadi lebih baik, penanganan service request penyelesaian kasus lebih terstruktur, dan akses kepada knowledge menjadi lebih mudah dan cepat. Threat, ancaman-ancaman yang dihadapi antara lain: resistence to change dari user, keengganan user untuk beradaptasi menggunakan prototype aplikasi KM ataupun saling berbagi knowledge dapat menjadi ancaman yang signifikan.

\section{Fase kedua: Analisis, Perancangan, dan Pengembangan Sistem}

Berdasarkan informasi yang telah didapat dari fase pertama, maka pada fase kedua ini peneliti menganalisis, merancang, dan mengembangkan Knowledge Management System dengan melakukan tahapan-tahapan sebagai berikut, yaitu: (1) merancang knowledge management platform; (2) mengidentifikasi knowledge di subdivisi Orafin; (3) merancang tim untuk KM; (4) membuat blueprint dari sistem $\mathrm{KM}$; (5) mengembangkan prototype aplikasi KM.

\section{Langkah Ketiga: Merancang Knowledge Management Platform}

Dari hasil observasi dan pengumpulan informasi terhadap infrasruktur yang berjalan pada tahap pertama, maka platform yang paling sesuai untuk prototype aplikasi KM ini adalah web application platform. Untuk pengembangan prototype aplikasi KM di subdivisi Orafin, peneliti memilih aplikasi Windows Sharepoint Services, dengan pertimbangan: sistem yang dibutuhkan sudah tersedia di Subdivisi Orafin, lebih fleksibel dan mudah untuk dikustomisasi sesuai dengan kebutuhan tanpa harus banyak melakukan penambahan coding, fitur-fitur dan settingan yang sudah ada lebih lengkap dan lebih detail, dan kapasitas penyimpanan data lebih besar dan maintenace data lebih mudah dengan menggunakan SQL Server Management Studio.

\section{Langkah Keempat: Identifikasi Knowledge pada Subdivisi Orafin}

Identifikasi knowledge dilakukan untuk mengetahui kebutuhan knowledge apa saja yang penting untuk disimpan pada prototype aplikasi KM, sehingga dapat memenuhi kebutuhan user akan knowledge. Pada tahap ini peneliti akan membahas: modul-modul pada Oracle Financial dan knowledge pada subdivisi Oracle Financial. Berikut ini akan dibahas tiap poin di atas dengan lebih rinci.

\section{Modul-modul pada Oracle Financial}

Sebagai tahap awal identifikasi knowledge, peneliti mempelajari proses bisnis dari masing-masing modul yang ada pada Oracle Financial (Orafin). Orafin terdiri dari 5 modul, yaitu accounts payables, accounts receivables, general journal, fixed assets, dan cash management.

\section{Knowledge pada Subdivisi Orafin}

Setelah mempelajari proses bisnisnya, maka dapat diidentifikasi knowledge yang ada pada modul-modul Orafin di antaranya meliputi:

\section{Proses Bisnis dari Setiap Modul}

Proses bisnis dari setiap modul yang dipegangnya merupakan knowledge dasar yang harus dimiliki oleh setiap user, sehingga mereka dapat memahami urutan terjadinya transaksi, serta proses yang harus dilakukan pada akhir periode sesuai dengan prosedur yang telah ditetapkan. Untuk itu, subdivisi Orafin sudah memiliki Standard Operating Procedure (SOP) dalam bentuk file yang ditempatkan di file server.

\section{Keterangan, Panduan Penggunaan, dan Cara Input pada Setiap Form di Aplikasi Oracle}

User harus mengetahui field-field mana saja yang wajib diisi dari setiap form transaksi ataupun form set up data master, serta field-field tersebut harus diisi dengan data yang valid, agar data-data yang di-input ke aplikasi dapat diolah dengan benar dan ditampilkan pada report-report yang bersangkutan. User wajib untuk mengetahui karakteristik setiap tipe transaksi yang ada pada masing-masing modul agar transaksi diinput dengan tipe yang sesuai. Biasanya user manual untuk cara input transaksi pada setiap modul dibagikan kepada user peserta training dalam bentuk hardcopy.

\section{Cara-Cara Untuk Mengkoreksi Transaksi dan Mengatasi Kasus yang Sering Terjadi}

User juga perlu memahami cara untuk melakukan koreksi pada kondisi tertentu. Misalnya, untuk invoice tipe Prepayment, setelah validate tidak dapat di-reverse, tetapi harus dengan cara Cancel untuk membatalkannya. User juga perlu mengetahui cara mengatasi kasus yang biasanya sering terjadi seperti selisih antara modul GL dan AP, langkah awal untuk mencari penyebab selisihnya adalah dengan memeriksa apakah ada jurnal manual di GL untuk akun yang selisih tersebut. Knowledge untuk pemecahan kasus seperti ini lebih bersifat tacit, meningkat seiring dengan bertambahnya pengalaman kerja karyawan.

\section{Fungsi dan Cara Run Report Beserta Parameternya}

Masing-masingmodulOrafinmemilikireporttersendiri untuk menampilkan data-data transaksi sesuai dengan fungsi dan parameter tertentu. Untuk mendapatkan informasi yang dibutuhkan, user harus mengetahui fungsi report, persyaratan apa saja yang harus terpenuhi agar data dapat ditampilkan di report, serta penggunaan parameternya. Untuk dokumentasi daftar report apa saja yang ada pada modul Orafin sudah ada, namun belum di-share untuk semua user.

\section{Langkah Kelima: Merancang Tim untuk Knowledge Management}

Untuk rancangan tim untuk proyek knowledge management dibedakan menjadi 2, yaitu (1) tim pengembang awal dari prototype aplikasi knowledge management dan (2) tim maintenance, pengembang, dan pengguna dari prototype aplikasi knowledge management.

\section{Tim Pengembang Awal dari Prototype Aplikasi Knowledge Management}

Pada tabel di bawah ini, diuraikan peran dan karakteristik dari tim pengembangan awal prototype aplikasi KM pada subdivisi Orafin (lihat Tabel 1). 


\section{Tim Maintenance, Pengembang, dan Pengguna dari Prototype Aplikasi Knowledge Management}

Job description dari masing-masing anggota tim maintenance, pengembang, dan pengguna dari prototype aplikasi KM, yaitu: (1) tim software, sebagai administrator yang melakukan setting prototype aplikasi KM (add user, setting menu, add/remove section \& category); (2) tim hardware, trouble shooting (konfigurasi server and aplikasi); (3) staf orafin, mengumpulkan dan membuat dokumentasi dari knowledge-knowledge yang sudah ada untuk di-input ke dalam knowledge base, melakukan add/remove articles, dan help desk support; (4) Orafin supervisor, melakukan approval terhadap semua knowledge baru baik articles atau comment baru yang akan dimasukkan ke dalam aplikasi dan memberikan supervisi mengenai knowledge apa saja yang penting untuk di-input ke dalam knowledge base; (5) Orafin manager, sebagai team leader, membuat perencanaan dan strategi untuk pengembangan knowledge lebih lanjut pada subdivisi Orafin; (6) technology and information manager, sebagai penggerak yang mendukung perancangan prototype aplikasi KM dan menetapkan kebijakan prosedur dan sosialisasi penggunaan prototype; (7) divisi pembukuan dan keuangan, merupakan end user yang merupakan pengguna dari prototype aplikasi KM untuk memperoleh informasi dan knowledge.

\section{Tahap Keenam: Membuat Blueprint dari Sistem Knowledge Management}

Pada blueprint dari sistem knowledge management ini, peneliti mencoba menggambarkan secara detil mengenai rancangan dari prototype aplikasi KM yang akan dikembangkan, yaitu:

Tabel 1 Rancangan Tim Proyek Knowledge Management

\begin{tabular}{|c|c|c|c|}
\hline Fokus & $\begin{array}{c}\text { Shareholder } \\
\text { Group }\end{array}$ & $\begin{array}{l}\text { Perannya pada Proyek } \\
\text { Knowledge Management }\end{array}$ & $\begin{array}{c}\text { Karakteristik yang } \\
\text { dibutuhkan }\end{array}$ \\
\hline Tim & Tim Orafin & $\begin{array}{l}\text { Menyedikan keahlian fungsional } \\
\text { dan bisnis yang ada pada modul } \\
\text { Orafin. } \\
\text { Berpartisipasi pada tahap proses } \\
\text { perancangan prototype aplikasi } \\
\text { KM sesuai dengan kebutuhan } \\
\text { akan knowledge. }\end{array}$ & $\begin{array}{l}\text { Mengerti proses bisnis pada } \\
\text { modul Orafin. } \\
\text { Memiliki keahlian } \\
\text { interpersonal dan tim yang } \\
\text { baik. } \\
\text { Bersedia untuk melihat dari } \\
\text { sudut pandang fungsional } \\
\text { lainnya. }\end{array}$ \\
\hline
\end{tabular}

\begin{tabular}{|c|c|c|c|}
\hline Teknologi & $\begin{array}{c}\text { Tim Software dan } \\
\text { Hardware }\end{array}$ & $\begin{array}{l}\text { Menyediakan keahlian dari sisi } \\
\text { teknologi dan jaringan. } \\
\text { Mengembangkan prototype } \\
\text { aplikasi secara teknis. } \\
\text { Berpartisipasi langsung dalam } \\
\text { instalasi prototype aplikasi KM. } \\
\text { Memberikan perspektif mengenai } \\
\text { kapabilitas dari fungsional dan } \\
\text { keterbatasan sistem ataupun } \\
\text { teknologi yang sudah ada } \\
\text { sekarang. }\end{array}$ & $\begin{array}{l}\text { Mengerti teknologi dengan } \\
\text { baik. } \\
\text { Mempunyai kemam-puan } \\
\text { interpersonal yang baik. } \\
\text { Bersedia untuk memahami } \\
\text { perspektif yang diberikan } \\
\text { oleh anggota tim lainnya } \\
\text { dan secara aktual mampu } \\
\text { menggabungkannya ke } \\
\text { dalam rancangan. }\end{array}$ \\
\hline Organisasional & $\begin{array}{l}\text { Technology } \\
\text { \&Information } \\
\text { Manager }\end{array}$ & $\begin{array}{l}\text { Mendukung legitimasi proyek. } \\
\text { Memberikan visi yang berkorelasi } \\
\text { dengan keseluruhan visi } \\
\text { perusahaan secara luas. } \\
\text { Mendukung sumber daya yang } \\
\text { diperlukan. } \\
\text { Mendukung kebijakan untuk } \\
\text { sosialisasiknowledgemanagement } \\
\text { dan budaya knowledge sharing. }\end{array}$ & $\begin{array}{l}\text { Memahami proses } \\
\text { manajemen dan strategis. } \\
\text { Memiliki kredibilitas. } \\
\text { Memiliki posisi } \\
\text { kepemimpinan yang kuat } \\
\text { di mana semua anggota tim } \\
\text { dapat menerimanya. } \\
\text { Memiliki gagasan yang } \\
\text { jelas mengenai gambaran } \\
\text { yang lebih besar dari di } \\
\text { mana seharusnya knowledge } \\
\text { berada pada perusahaan. }\end{array}$ \\
\hline
\end{tabular}

\section{Modul-Modul pada Prototype Aplikasi Knowledge Management}

Berikut ini adalah modul-modul yang akan dibangun pada prototype aplikasi KM, yaitu wiki page, document library, discussions board, blog, picture library, knowledge base, help desk, frequently asked questions (FAQ), survey, dan setting.

\section{Rancangan Struktur Menu Prototype Aplikasi Knowledge Management}

Berikut ini adalah gambar dari rancangan struktur menu pada prototype aplikasi KM (lihat Gambar 5). 


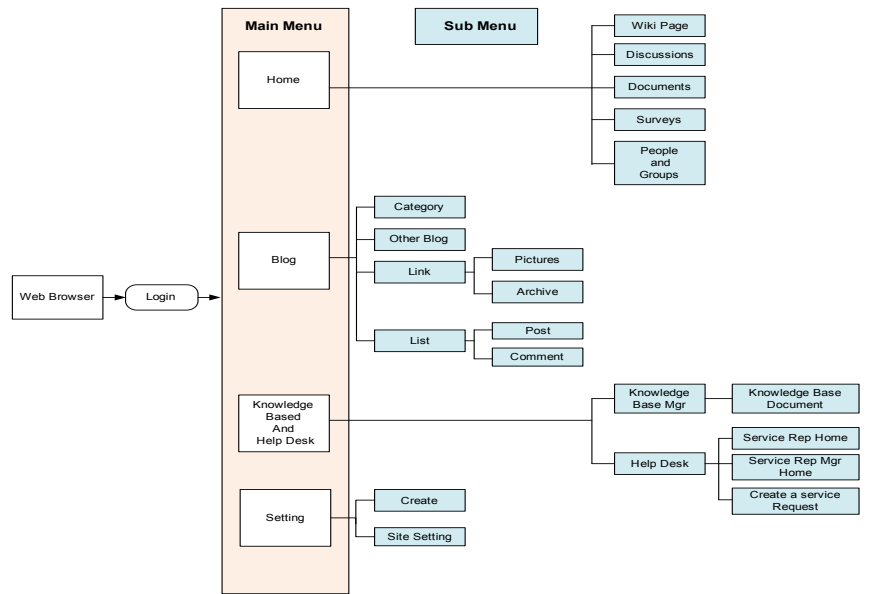

Gambar 5 Struktur Menu Prototype Aplikasi Knowledge Management

Prosedur penanganan kasus yang berjalan saat ini adalah (seperti pada Gambar 6):



Gambar 6 Workflow Pengangan Kasus yang Berjalan Sekarang

Ketika ada masalah, bagian operasional pembukuan akan mengirimkan masalah tersebut via e-mail untuk dicarikan solusinya. Kemudian staff Orafin akan me-review kasus yang dikirimkan. Jika staf Orafin sudah langsung mengetahui solusinya maka solusi tersebut dikirimkan kepada bagian operasional. Jika solusi tersebut dapat digunakan untuk menyelesaikan permasalahan yang terjadi, maka kasus terpecahkan dan selesai. Namun jika staf Orafin tidak mengetahui solusinya, maka ia akan bertanya dan mengkonsultasikan masalah tersebut kepada staf Orafin. Supervisor Orafin akan memberikan masukan dan saran dari pemecahan masalah. Jika solusi yang diberikan oleh supervisor dapat memecahkan masalah, maka kasus terpecahkan dan selesai. Namun jika, solusi tersebut tidak sesuai atau supervisor sendiri belum pernah menangani kasus serupa maka permasalahan tersebut akan menjadi new issue untuk dilakukan riset agar dapat ditemukan solusi untuk permasalahan baru tersebut.

Solusiyang dihasilkan dari risetakan dikirimkan kepada bagian operasional sebagai jawaban dari permasalahannya.

Kelemahan utama dari prosedur penanganan masalah yang berjalan sekarang adalah solusi yang didapatkan dari hasil riset tidak didokumentasikan sehingga jika terjadi kasus serupa sulit untuk mencari referensinya. Adapun rancangan workflow KM yang diajukan (lihat Gambar 7).

Proses Learning, yaitu user dapat membaca dan mempelajari knowledge yang disimpan pada knowledge base. Jika user mempunyai informasi atau pengetahuan yang ingin di-share mereka dapat menambahkan artikel atau komentar atas suatu artikel. Artikel atau komentar tersebut akan melalui proses approval oleh supervisor Orafin.Jika artikel atau komentar di-approve, maka akan disimpan di dalam knowledge base dan di-publish sehingga user lain dapat membacanya.

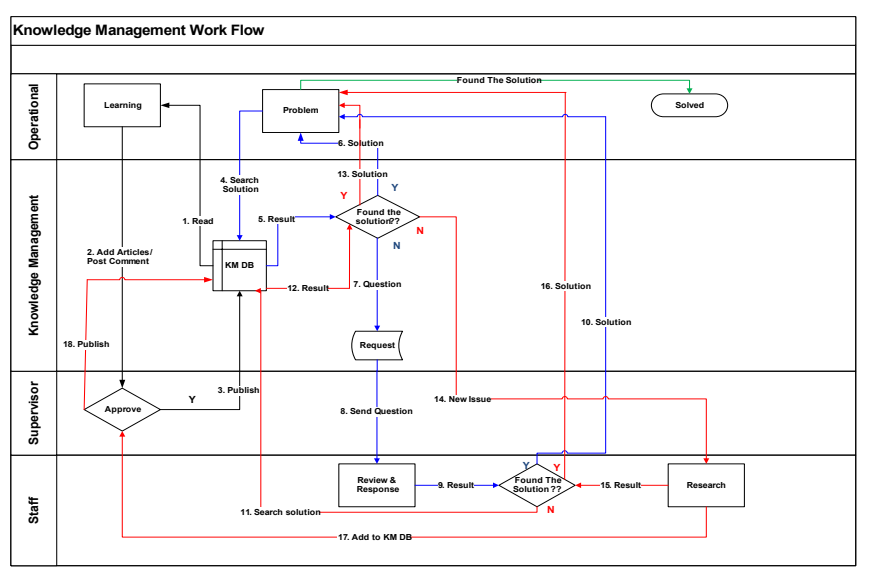

Gambar 7 Rancangan Workflow Knowledge Management

Proses penanganan masalah atau kasus, yaitu ketika ada masalah atau kasus, bagian operasional dapat mencari solusinya terlebih dahulu pada knowledge base. Knowledge base akan menampilkan hasil pencarian. Jika solusi yang ditemukan pada knowledge base sesuai, maka kasus tersebut terselesaikan. Namun jika tidak ditemukan solusi yang sesuai, bagian operasional dapat mengirimkan pertanyaannya melalui aplikasi KM. Pertanyaan atau masalah tersebut akan dikirimkan kepada staff Orafin untuk di-review. Jika staff Orafin sudah langsung mengetahui solusinya maka solusi tersebut dikirimkan kepada bagian operasional. Jika solusi tersebut sesuai maka kasus terpecahkan dan selesai. Jika staff Orafin belum mengetahui solusinya, maka ia dapat mencari pada knowledge base apakah kasus serupa pernah terjadi dan sudah ada solusinya. Knowledge base akan menampilkan hasil pencarian. Jika solusi yang ditemukan pada knowledge base sesuai, maka kasus tersebut terselesaikan. Namun jika tidak ditemukan solusi yang sesuai, maka akan menjadi new issue untuk dicari solusinya dengan melakukan riset dan testing pada aplikasi dummy. Hasil riset sebagai jawaban dari permasalahan. Hasil riset tersebut akan dikirimkan kepada bagian operasional. Hasil riset juga akan disimpan ke dalam knowledge base, namun sebelumnya harus melewati proses approval dari supervisor Orafin. Hasil riset yang di-approve oleh supervisor akan disimpan di dalam knowledge base dan dipublikasi.

Kelebihan dari rancangan workflow KM yang peneliti ajukan antara lain solusi yang dihasilkan dari riset disimpan dan dapat diakses kembali ketika dibutuhkan, dengan knowledge yang tersimpan dan diorganisasikan pada knowledge base memotivasi user untuk lebih aktif baik dalam knowledge sharing dengan berpartisipasi menambahkan artikel ataupun lebih berinisiatif untuk mencari sendiri solusi dari kasusnya.

\section{Tahap Ketujuh: Mengembangkan Prototype Aplikasi Knowledge Management}

Prototype aplikasi KM ini dikembangkan dengan menggunakan aplikasi SharePoint. Berikut ini adalah spesifikasi software dan hardware yang diperlukan:

Tabel 2 Requirement software untuk pengembangan prototype aplikasi knowledge management

\section{Software}




\begin{tabular}{ll}
\hline \multicolumn{1}{c}{ Software } & \multicolumn{1}{c}{ Description } \\
\hline Windows Server 2003 & Operation System \\
IIS (Internet Information & Web Server \\
Services) 6.0 & \\
.Net Frame Work 2.0 and 3.0 & Frame work for running Share Point \\
SQL Sever 2005 & Data Base Server \\
Windows Share Point & Main Application \\
Services 3.0 & For create and open MS Office \\
Microsoft Office 2007 & Documents \\
\hline
\end{tabular}

Sumber: Determine Hardware and Software Requirements (Windows SharePoint Services), 2009, http://technet.microsoft. com/en-us/library/cc288751.aspx

Tabel 2 Requirement hardware untuk server prototype aplikasi knowledge management

\begin{tabular}{|c|c|c|}
\hline Component & Minimum & Recommended \\
\hline Processor & 2.5 gigahertz $(\mathrm{GHz})$ & $\begin{array}{l}\text { Dual processors that are each } \\
3 \mathrm{GHz} \text { or faster }\end{array}$ \\
\hline RAM & 1 gigabyte (GB) & $2 \mathrm{~GB}$ \\
\hline Disk & $\begin{array}{l}\text { NTFS file system- } \\
\text { formatted partition with a } \\
\text { minimum of } 3 \mathrm{~GB} \text { of free } \\
\text { space }\end{array}$ & $\begin{array}{l}\text { NTFS file system-formatted } \\
\text { partition with } 3 \mathrm{~GB} \text { of free } \\
\text { space plus adequate free } \\
\text { space for your Web sites }\end{array}$ \\
\hline Drive & DVD drive & $\begin{array}{l}\text { DVD drive or the source } \\
\text { copied to a local or network- } \\
\text { accessible drive }\end{array}$ \\
\hline Display & $1024 \times 768$ & $\begin{array}{l}1024 \times 768 \text { or higher } \\
\text { resolution monitor }\end{array}$ \\
\hline Network & $\begin{array}{l}56 \text { kilobits per second } \\
\text { (Kbps) connection } \\
\text { between client computers } \\
\text { and server }\end{array}$ & $\begin{array}{l}56 \mathrm{Kbps} \text { or faster connection } \\
\text { between client computers } \\
\text { and server }\end{array}$ \\
\hline
\end{tabular}

Sumber: Determine Hardware and Software Requirements (Windows SharePoint Services), 2009, http://technet.microsoft. com/en-us/library/cc288751.aspx

\section{Evaluasi Rancangan Prototype Aplikasi Knowledge Management}

Peneliti menggunakan tool kuisioner online yang terintegrasi dengan prototype aplikasi KM. Responden dari kuisioner ini adalah subdivisi Orafin, divisi pembukuan dan keuangan untuk BU Sweet Water dengan jumlah responden 20 orang. Jawaban responden pada kuisioner dianalisis dengan skala Likert untuk memperoleh kesimpulan mengenai efektivitas rancangan prototype aplikasi knowledge management, apakah tujuan dan manfaat dari proyek perancangan prototype aplikasi KM tercapai. Peneliti menggunakan instrumen yang terdiri dari 8 pertanyaan, maka perhitungan skor-skornya sebagai berikut:

$$
\begin{aligned}
& 8 \times 5=40 \text { (sangat efektif) } \\
& 8 \times 3=24 \text { (rata-rata efektif) } \\
& 8 \times 1=8 \text { (tidak efektif) }
\end{aligned}
$$

Berdasarkan hasil pengolahan kuisioner maka nilai yang diperoleh adalah 29.7 (didapat dari $594 / 20=29.7$ ) yang berarti berada di atas nilai rata-rata efektif, jadi dapat disimpulkan bahwa perancangan prototype aplikasi KM ini sudah dapat memenuhi sebesar $74.25 \%$ (didapat dari 29.7 / $40=74.25 \%$ ) dari tujuan dan manfaat proyek. Persentase didapat dari rata-rata nilai responden 29.7 dibagi dengan nilai yang sangat efektif 40 dan dikalikan dengan $100 \%$.

\section{PENUTUP}

Simpulan yang diperoleh dari perancangan prototype aplikasi knowledge management pada subdivisi Oracle Financial di Orang Tua Group adalah: (1) perancangan prototype knowledge management dikembangkan dengan program Sharepoint dan berfokus pada strategi codification untuk memungkinkan penyimpanan, pemberian index, perolehan, dan penggunaan kembali knowledge; (2) prototype aplikasi knowledge management dapat memfasilitasi user dalam berbagi knowledge dan mengoptimalkan penggunaannya dengan menyediakan manajemen dokumen untuk berbagai keperluan seperti request set up, dokumen user manual, daftar report, fitur forum diskusi, serta help desk; (3) prototype aplikasi knowledge management dapat menyimpan knowledge dan pengalaman karyawan yang bermanfaat baik pada saat ini ataupun di masa yang akan datang; (4) dengan penggunaan prototype aplikasi knowledge management dapat mengurangi waktu yang dibutuhkan untuk pemecahan kasus, karena dapat menggunakan solusi yang tersimpan pada knowledge base dan riset hanya dilakukan untuk masalah-masalah baru; (5) perancangan prototype knowledge management yang dikembangkan telah mampu menjawab semua permasalahan dalam proyek yang telah dijelaskan sebelumnya; (6) perancangan prototype knowledge management yang peneliti lakukan sudah dapat memenuhi tujuan dan manfaat proyek sebesar $74.25 \%$ berdasarkan hasil analisis kuisioner.

Olehkarenaitu, diperlukanadanyasuatukebijakandari pimpinan untuk mengembangkan dan mengimplementasikan prototype aplikasi knowledge management yang telah dibuat agar dapat digunakan secara maksimal untuk memenuhi kebutuhan user dalam berbagi knowledge. Manajemen harus berperan serta dalam melakukan sosialisasi akan pentingnya knowledge dan mendukung penggunaan prototype aplikasi knowledge management. Tim Oracle Financial sebagai admin prototype aplikasi knowledge management perlu melakukan maintainance terhadap aplikasi dan knowledge yang disimpan agar tetap up-to-date dan dapat digunakan secara optimal. Tim Software dapat melakukan pengembangan prototype aplikasi knowledge management dengan menambahkan fitur rating untuk memonitor aktivitas dan partisipasi user, sehingga dapat diketahui user yang paling aktif dan berhak mendapat predikat "KM Star" jika kebijakan reward diberlakukan oleh manajemen.

\section{DAFTAR PUSTAKA}

Microsoft (2009), Hardware and software requirements (SharePoint Foundation 2010). Microsoft TechNet. http://technet.microsoft. com/en-us/library/cc288751.aspx

Thompson, A. A., Strickland, A. J., \& Gamble, J. E. (2008). Crafting \& executing strategy: the quest for competitive advantage concepts and cases (16th ed.). New York: McGraw Hill.

Tiwana, A. (2002). The knowledge management toolkit (2nd ed.). Prentice Hall. 